\title{
マルチスケール気液界面モデル*
}

$$
\text { 米本幸 弘*1, 功 刀資 彰*2 }
$$

\section{Multi-Scale Gas-Liquid Interfacial Model}

\author{
Yukihiro YONEMOTO and Tomoaki KUNUGI*3
}

\author{
${ }^{* 3}$ Department of Nuclear Engineering, Kyoto University, \\ Yoshida, Sakyo-ku, Kyoto-shi, Kyoto, 606-8501 Japan
}

\begin{abstract}
At a gas-liquid interface, there are many physics and unknown phenomena related to thermodynamics, electromagnetics, hydrodynamics, and heat and mass transfer. Therefore, a modeling of gas-liquid interface is one of key issues of the numerical research on multiphase flow. Currently, the Continuum Surface Force model (CSF) is popular to model a gas-liquid interface in computational fluid dynamics. However, the CSF model cannot explain the physics of the gas-liquid interface because this model is derived by a mechanical energy balance at the interface. In this study, assuming that the interface is a thin fluid-membrane and has a finite thickness, we develop a new gasliquid interfacial model based on thermodynamics via mathematical approach. In particular, we derive the equation of free energy based on a lattice gas model including the effect of the electric double layer caused by a contamination on the interaction between the bubble interfaces. Finally, we derive a set of new governing equations of fluid motion based on a mesoscopic concept and the free energy is incorporated into the Navier-Stokes equation as the new terms by using Chapman-Enskog expansion.
\end{abstract}

Key Words: Multi-Phase Flow, Interfacial Phenomena, Bubble, Liquid Droplet, Micro-Bubble

\section{1. 粕 言}

気相と液相の境界である界面は，巨視的な観点では 物性值の不連続性を特徵としてモデル化されるが，原 子・分子レベルの微視的な観点では両相は連続してい る.このような気液界面の持つ多重スケール構造性を いかにモデル化するかが混相流数值解析的研究にお ける長年の課題である.

現在最も広く用いられている Brackbill等によるCSF モデル(1) では, 界面を力学的釣り合いから計算格子幅 程度の遷移領域として捉え, 表面張力を遷移領域に働 く体積力に置き換えてモデル化しているため, 界面の 安定性や多重スケール構造等を特徴づける界面の物 理を考慮することができない，本来，界面では物理化 学や熱・物質移動等など, 様々な物理が複雑に関係し

* 原稿受付 2007 年 3 月 19 日。

*1 京都大学大学院工学研究科原子核工学専攻( 4 606-8501 京 都市左京区吉田本町).

*2 正員, 京都大学大学院工学研究科原子核工学専攻

E-mail : kunugi@ nucleng.kyoto-u.ac.jp
ており，特に界面相互作用では界面に付着した污れ物 質による電荷の影響等は考慮すべきであろう (2).

近年, 材料組織の 2 元合金の相転移に関する研究で 用いられている van der Waals 理論 (3) や Cahn-Hilliard 等 ${ }^{(4)}$ による理論を数值解析一応用した Phase Field 法 が，流体解析において注目を集めている。これは，界 面を有限幅の遷移領域として扱い，不均一系の自由エ ネルギー汎関数を拡散式に結び付けることにより導 出された Cahn-Hilliard 方程式の時間発展を計算する事 で現象を扱う方法である.この Phase Field 法のように 熱力学的に界面を捉えることは，従来モデル化できな かった界面の物理を考慮できることを意味している. そこで, 本研究では, 界面をある種の膜と仮定し, 界 面膜内の自由エネルギーについて熱力学的な観点か ら考察を行う. そして, 気泡合一・分裂挙動といった 界面間相互作用に深く関係していると考えられる，表 面電荷の影響を考慮した自由エネルギー式を微視的 なスケールから導出した. そして, 得られた式を, Navier-Stokes (NS)方程式に Chapman-Enskog 展開を援 用することにより数学的に組み込み, 新たな混相流体 方程式を導出し，その方程式の可能性を考察した. 


\section{2. 主な記号}

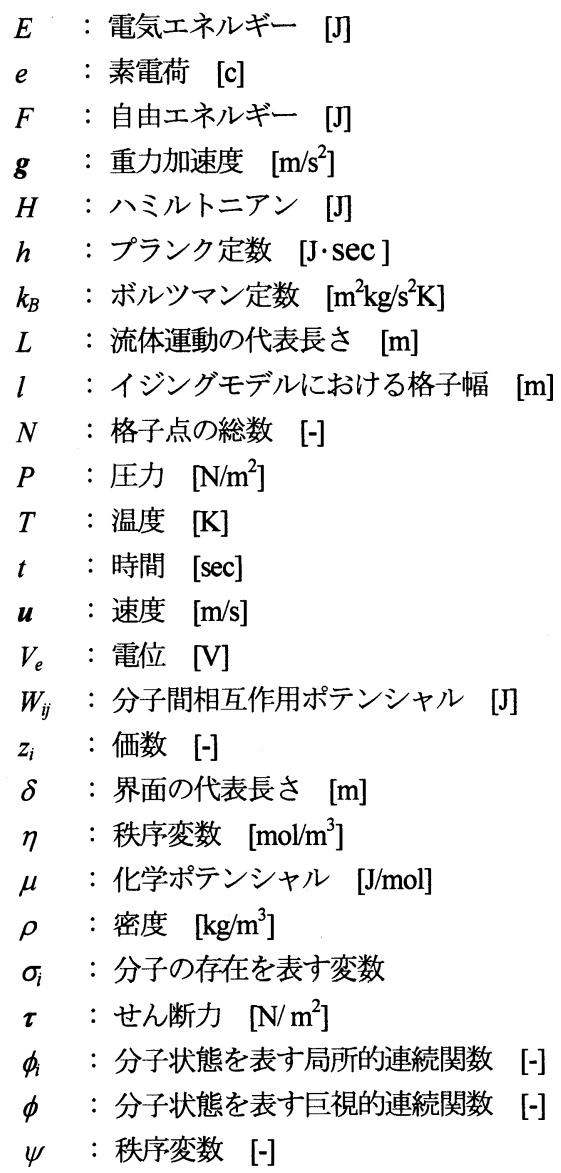

\section{3. 電荷の效果を含んた泊由エネルギ}

気液2相間で,バルクの平衡が成り立っている系では，相 分離により 2 相を隔てる界面が存在する。熱力学的には， 界面の存在は自由エネルギーの存在を意味する。 そこで， 本節ではこの自由エネルギーを分子間相互作用といった 微視的スケールから考察し，具体的な自由エネルギー式の 導出を行うの。白の際，界面に付着した污れ物質による電 荷の影響を含めた議㷍を行う。

3-1 ハミルトニアン イジングモデルは磁場中 の磁性体の相転移を説明するモデルであるが，通常の 単純な気体や液体間の相転移現象においても同様な 議論が行え，それは格子気体と呼ばれている。 まず， 図 1 に示す格子幅 $l$ の 2 元系 3 次元立方格子上でイジ ングモデルを考える．格子点( $(i)$ は変数 $\sigma_{i}$ を持ち, $\sigma_{i}$ は 1 か00值をとるものとする. 格子気体モデルでは, 格子点(i)において $\sigma_{i}=0$ の時は $\mathrm{A}$ 分子, $\sigma_{i}=1$ の時は $\mathrm{B}$ 分子が存在していると考える. また, 以下の仮定を前 提条件に置いている.

[1] 1 つの位置に 2 つ上の分子は存在しない.

[2]A,B 分子間は 2 体の相互作用のみしか働かない。 [3]A,B 分子のサイズ及び形状は同じ.

[4]分子間力は近距離力のみ.

このとき取り扱う溶液は正則溶液を想定している. 本 研究では, さらに界面に付着した污れ物質により生じ た電荷の影響を電気二重層としてモデル化する. 簡単 のため, すでに界面上には污れ物質が存在しており， 吸着分布は一様であると仮定するが，吸着過程は省略 する. 界面に吸着している污れ物質による電荷の影響 は，点電荷が空間に分布したポテンシャルからの影響 と考え，場に作用する力と見なす. 上記の議論を基に， 自由エネルギー式の導出を行う。

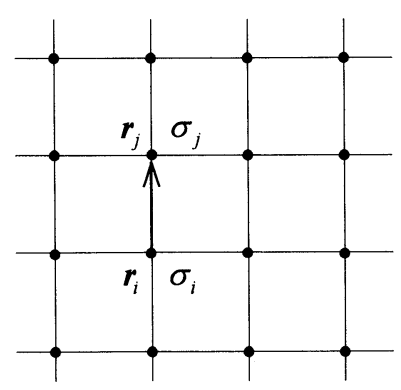

Fig. 1 Two-dimensional lattice in Ising model:

$$
\begin{aligned}
& \sigma_{i}=0 \rightarrow \text { Molecular } A, \\
& \sigma_{i}=1 \rightarrow \text { Molecular } B, l=\left|\boldsymbol{r}_{j}-\boldsymbol{r}_{i}\right| .
\end{aligned}
$$

本体系における八ミルトニアン $H$ 及び電気エネル ギーEは以下のようになる.

$$
\begin{aligned}
& H=-\frac{1}{2} \sum_{i=1}^{N} \sum_{j=1}^{N} Y_{i j}+E, \\
& E=-\frac{1}{2} \sum_{i=1}^{N} z_{i} e V_{e}\left(\boldsymbol{r}_{i}\right) \sigma_{i}, \\
& Y_{i j}=W_{i j}^{A A}\left(1-\sigma_{i}\right)\left(1-\sigma_{j}\right)+W_{i j}^{B B} \sigma_{i} \sigma_{j} \\
& +W_{i j}^{A B}\left[\sigma_{i}\left(1-\sigma_{j}\right)+\sigma_{j}\left(1-\sigma_{i}\right)\right] .
\end{aligned}
$$

ここで, $N$ は格子点の総数を表し, $W_{\mathrm{ij}}$ は粒子間相互作 用ポテンシャルである、条件[1], [2], [3] 及び[4]を考慮 し，式(3)を展開・整理することにより，以下の式を得 る.

$$
Y_{i j}=-\left(W_{i j}^{A A}+W_{i j}^{B B}-2 W_{i j}^{A B}\right) \sigma_{i}\left(1-\sigma_{j}\right),
$$




$$
U_{i j}=W_{i j}^{A A}+W_{i j}^{B B}-2 W_{i j}^{A B} .
$$

ここで, $U_{\mathrm{ij}}$ は正味の粒子間相互作用ポテンシャルであ る.式(4)及び(5)を用いることにより式(1)は以下のよう になる.

$$
H=\frac{1}{2} \sum_{i=1}^{N} \sum_{j=1}^{N} U_{i j} \sigma_{i}\left(1-\sigma_{j}\right)+E \cdot
$$

上式が電荷の効果を考慮したハミルトニアンである.

3 -2 自由エネルギ一の決定 2 体系を除いて一 般の多体系では, 式(6)の分配関数を厳密に求めること は困難である．そこで，このハミルトニアンの分配関 数を直接に求めるのではなく, 対象の系を近似する自 由エネルギー $F$ をある条件を基準として，近似法によ り求める. この一連の手順はボゴリュボフ変分定理と 呼ばれ, 以下のボゴリュボフ不等式がその基淮を与え る条件である.

$$
F \leq F_{0}+\left\langle H-H_{0}\right\rangle_{0} \cdot
$$

$H ， F$ は興味ある系におけるハミルトニアン及びへル ムホルツの自由エネルギーであり， $H_{0}, F_{0}$ は可解モデ ル系におけるものである（ここでは，自由エネルギー 及び分配関数が既知の系を可解モデル系と呼ぶことに する）. 可解モデル系におけるへルムホルツ自由エネ ルギー $F_{0}$ 及び分配関数 $Z_{0}$ は,

$$
\begin{aligned}
& F_{0}=-k_{B} T \ln Z_{0}, \\
& Z_{0}=\int_{\Gamma} \exp \left(-\frac{H_{0}}{k_{B} T}\right) d \bar{\Gamma}, \\
& d \bar{\Gamma}=\frac{d p d q}{(2 \pi \hbar)^{3}},
\end{aligned}
$$

である.ここで， $d \bar{\Gamma}$ は位相空間における積分記号を 表しており, 空間座標 $\boldsymbol{p}$ 及ひ運動量 $\boldsymbol{q}$ から構成される. $(2 \pi \hbar)^{3}$ は分配関数を規格化するための係数であり, $\bar{\Gamma}$ 空間の微小体積を表す.この規格化は量子力学の不確 定性原理 $d p_{i} d q_{j} \cong 2 \pi \hbar(i, j=1,2,3)$ の考察に基づいて いる. $\hbar=h / 2 \pi$ であり, $h$ はプランク定数である.

式(7)は注目している系における自由エネルギーの 上限を与え，この式に基づき右辺が最小になる解を求 めることにより，最適な自由エネルギーが得られる. $H_{0}$ は, 式(6)に平均場理論を適用することにより決まる. これは, 双一次形式 $\sigma_{i} \sigma_{j}$ を一次形式 $\beta_{i} \sigma_{i}$ に置き換え ることを意味する.ここで, $\beta_{i}$ は式(7)の右辺を最小に
するための変数である. 以上より, 可解モデル系にお けるハミルトニアン $H_{0}$ は,

$$
H_{0}=\sum_{i=1}^{N} k_{B} T \beta_{i} \sigma_{i}-\frac{1}{2} \sum_{i=1}^{N} z_{i} e V_{e}\left(\boldsymbol{r}_{i}\right) \sigma_{i}
$$

となる. $k_{\mathrm{B}}$ はボルツマン定数， $T$ は系における温度を 表す. 式(11)及び $\sigma_{i}=1$ or 0 であることを考慮するこ とにより, 式(9)は以下のように変形される.

$$
\begin{aligned}
& Z_{0}=\prod_{i}^{N} \sum_{\sigma_{i}=1,0} \exp \left(-\bar{\beta}_{i} \sigma_{i}\right), \\
& \bar{\beta}_{i}=\beta_{i}-\frac{z_{i} e V_{e}}{2 k_{B} T} .
\end{aligned}
$$

また，式(12)を式(8)に代入することにより，以下の式 を得る.

$$
F_{0}=-\sum_{i}^{N} k_{B} T \ln \left[\exp \left(-\bar{\beta}_{i}\right)+1\right]
$$

注目している系と可解モデル系との間には，条件式(7) が保証されているため, 式(6), 式(8)及び式(11)を式(7) に代入すると,

$$
\begin{aligned}
& F \leq-k_{B} T \ln Z_{0} \\
& +\frac{1}{2} \sum_{i}^{N} \sum_{j}^{N} U_{i j}\left\langle\sigma_{i}\left(1-\sigma_{j}\right)\right\rangle_{0} \\
& -\sum_{i}^{N} k_{B} T \beta_{i}\left\langle\sigma_{i}\right\rangle_{0} .
\end{aligned}
$$

を得る. 右辺第2 項は可解モデル系における $\sigma_{i}$ であり， 線形化項として取り扱われる. そのため可解モデル系 の分配関数によって平均化された $\left\langle\sigma_{i} \sigma_{j}\right\rangle_{0}$ は, $\left\langle\sigma_{i}\right\rangle_{0}\left\langle\sigma_{j}\right\rangle_{0}$ のように分解される. これにより, 式(15) は以下のようになる.

$$
\begin{aligned}
& F \leq-k_{B} T \ln Z_{0} \\
& +\frac{1}{2} \sum_{i}^{N} \sum_{j}^{N} U_{i j}\left\langle\sigma_{i}\right\rangle_{0}\left(1-\left\langle\sigma_{j}\right\rangle_{0}\right) \\
& -\sum_{i}^{N} k_{B} T \beta_{i}\left\langle\sigma_{i}\right\rangle_{0} .
\end{aligned}
$$

このとき， $\left\langle\sigma_{i}\right\rangle_{0}$ は 0 から 1 まで連続值をとる. 式(16) の右辺を最小にするように変数 $\beta_{i}$ を決めることによ り，注目している系における最適な自由エネルギーが 求まる. 具体的には, $\left\langle\sigma_{i}\right\rangle_{0}$ を一定に保ちつつ, 式(16) を汎関数微分する. 従って, $\delta F / \delta \beta_{i}=0$ より,

$$
\left\langle\sigma_{i}\right\rangle_{0}=\frac{\exp \left(-\bar{\beta}_{i}\right)}{\exp \left(-\bar{\beta}_{i}\right)+1}
$$


を得る. $\left\langle\sigma_{i}\right\rangle_{0}=\phi_{i}$ として, 式(17)から $\beta_{i}$ を求める. このとき, 式(13)であることを考慮すると, 式(16)は以 下のようになる.

$$
\begin{gathered}
F=\sum_{i}^{N} k_{B} T\left[\left(1-\phi_{i}\right) \ln \left(1-\phi_{i}\right)+\phi_{i} \ln \phi_{i}\right] \\
-\sum_{i}^{N} \frac{1}{2} z_{i} e V_{e} \phi_{i}+\frac{1}{2} \sum_{i}^{N} \sum_{j}^{N} U_{i j} \phi_{i}\left(1-\phi_{j}\right) .
\end{gathered}
$$

式(18)は注目している系での自由エネルギーであり， 局所連続関数 $\phi_{i}$ を用いた自由エネルギーの離散型方 程式である.ここまでの熱力学的手順によって, 図 2-(a)で 0 もしくは 1 で表現されていた分子状態が, 図 2-(b)のように局所的に分布を持った状態で表現される ことになる. 局所的に連続とは言え，このスケールで は依然微視的スケールであるため, 巨視的連続スケー ルの自由エネルギーを得るために，式(18)に連続極限 を適用し，微分方程式に書き換える操作を行う.この 操作により，図2-(b)で表現される局所的に分布した分 子の状態が，図2-(c)のような格子幅 $l$ が認識できない ほどの巨視的連続スケールに極限近似されることに なる.

(c)
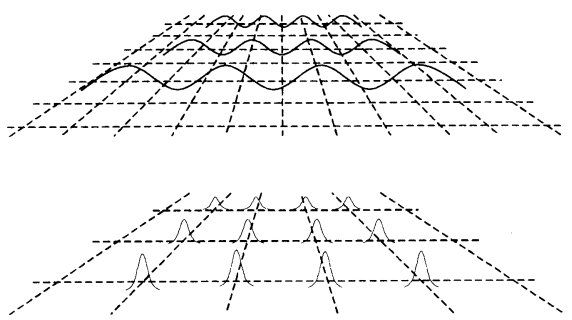

(b)

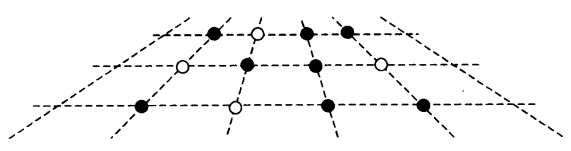

(a)

Fig. 2 Concept between micro- and macroscale: (a) shows lattice points (Distribution of $\sigma_{i}$ ) in which black point is molecular A and white one is molecular B, (b) shows local continuum (Distribution of $\phi_{i}$ ), (c) shows continuum limit (Distribution of $\phi$ ).

まず, 式(18)の右辺第 3 項の格子点 $i$ と $j$ の相互作用 を表す項を以下のように変形する.

$$
\begin{aligned}
& \frac{1}{2} \sum_{i}^{N} \sum_{j}^{N} U_{i j} \phi_{i}\left(1-\phi_{j}\right)= \\
& \frac{1}{4} \sum_{i}^{N} \sum_{j}^{N} U_{i j}\left[\left(\phi_{i}-\phi_{j}\right)^{2}-\phi_{i}^{2}-\phi_{j}^{2}+2 \phi_{i}\right] .
\end{aligned}
$$

もし，隣り合う分子との相互作用が近距離閒相互作用 のみであるなら, 最も近づく分子間距離を $l$ と仮定す ることで, 式(19)の右辺第 1 項は $l \rightarrow 0$ の極限操作によ り以下のように変形される.

$$
\left(\phi_{i}-\phi_{j}\right) n=\left(l \frac{\phi_{i}-\phi_{j}}{l}\right) n \underset{l \rightarrow 0}{\rightarrow} l \nabla \phi .
$$

つまり，

$$
\left(\phi_{i}-\phi_{j}\right)^{2}=l^{2}(\nabla \phi)^{2}
$$

である. ここで, $\phi_{i} \rightarrow \phi, \phi_{j} \rightarrow \phi$ とし, $\boldsymbol{n}$ は $\phi_{i}$ と $\phi_{j}$ 間 での単位べクトルである，さらにこのとき，連続極限

$(N \rightarrow \infty, l \rightarrow 0)$ をとれば,

$$
\frac{l^{3} \sum_{i}^{N}}{l^{3}}=\frac{l^{3} N}{l^{3}} \underset{l \rightarrow 0}{\rightarrow} \frac{d V}{l^{3}}
$$

となる. 結局, 以上の議論から, 式(18)は以下のよう になる。

$$
\begin{aligned}
& F=\int_{V}\left[f_{0}(\phi)+\frac{S}{2}(\nabla \phi)^{2}\right] d V, \\
& f_{0}(\phi)=\frac{1}{l^{3}}\left\{k_{B} T[\phi \ln \phi+(1-\phi) \ln (1-\phi)]\right. \\
& \left.+\frac{U}{2} \phi(1-\phi)\right\}-\frac{1}{2 l^{3}} z_{i} e V V_{e} \phi, \\
& S=\frac{U}{2 l}, \\
& U=\sum_{j}^{N} U_{i j} .
\end{aligned}
$$

式(23)は連続スケールの領域 $\mathrm{d} V$ における自由エネル ギーである.この式は, $\phi$ が濃度の関数と関連してい るため, 自由エネルギー沉関数と呼ばれている. 式(23) の右辺に関して, 第 1 項は均一場における自由エネル ギーであり，第2 項は不均一場における自由エネルギ 一を表す。ここで, 通常 $\phi=1 / 2$ は 2 相が区別できな い臨界状態を表すのであるが，本研究では，系が室温 状態である場合でも $\phi=1 / 2$ は気液界面を表すと解釈 する. そこで, 式(23)に関して, $\psi=\phi-1 / 2$ の臨界点 近傍で 4 次のテーラー展開を行うと，次式を得る. 


$$
\begin{gathered}
F=\int_{V}\left[f_{0}(\psi)+\frac{d}{2}(\nabla \psi)^{2}\right] d V, \\
f_{0}(\psi)=-\frac{a}{2} \psi^{2}+\frac{b}{4} \psi^{4}-c z_{i} e V_{e} \psi, \\
a=\frac{U-4 k_{B} T}{l^{3}}, \\
b=\frac{16 k_{B} T}{3 l^{3}}, \\
c=\frac{1}{2 l^{3}}, \\
d=\frac{U}{2 l} .
\end{gathered}
$$

この臨界点近傍での展開を Ginzuburg-Landau 展開と 呼び， 4 は注目している系を特徴づける秩序変数で ある.

\section{4. 自由エネルギーの解䣋}

本節では，NS方程式における自由エネルギーの解 釈及び圧力項への導入方法を考察する.

界面を伴った解析において, 従来の CSF モデルでは, 表面張力の評価に関して界面形状を特徴づける曲率 を用いていた，しかしながら，巨視的には不連続面で ある界面が, 連続的な密度遷移領域と解釈できるほど の微視的スケールでは, 界面形状を特徴付ける曲率の 定義が困難となり，表面張力の評価ができない.この ため, 微視的スケールでは, 表面張力を界面の形状等 で評価するのではなく，エネルギーから求めなければ ならない ${ }^{(6,7)}$. そこで, 熱力学的な圧力の定義である マクスウェルの関係式を用い，この圧力を界面内圧力 と解釈する.

$$
P=-\left(\frac{\partial F}{\partial V}\right)_{T} .
$$

よって, 式(27)を考慮すると，

$$
P_{\text {therm }}=f_{0}(\psi)+\frac{d}{2}(\nabla \psi)^{2}
$$

となる. 式(34)を界面内圧力と定義すると同時に，本 研究では界面をある種の流体膜と仮定しているので, その流体膜中における流動様式は, 法線方向に関して は拡散のみとし，接線方向では拡散及び流体運動が存 在すると仮定する.この時点では式(34)を NS 方程式に 導入する事はできない.これは，微視的スケール及び 巨視的スケールの間で起こるスケール間相互作用を 考慮しなければならないためである。そこで，
Chapman-Enskog 展開 ${ }^{(8)}$ を NS 方程式に適用してマル チスケールの相互作用を考慮した支配方程式の定式 化を試みる。まず，従来の NS 方程式は，

$$
\rho \frac{D \boldsymbol{u}}{D t}=-\nabla P+\nabla \cdot \tau+g
$$

である， $\rho, \boldsymbol{u}, P, \tau, \boldsymbol{g}$ 及び $\boldsymbol{t}$ は，それぞれ流体の 密度, 速度, 圧力, せん断力, 重力加速度及び時間で ある.ここで， $D / D \mathrm{t}$ 及び $\nabla$ の時間・空間を表す演算子 はマルチスケールとしての扱いが可能であると考え られる. そこで，場のスケールを特徴付ける微小パラ メーター $\varepsilon$ でそれぞれの演算子を展開すると，

$$
\begin{aligned}
\boldsymbol{\nabla} & =\boldsymbol{\nabla}^{(0)}+\boldsymbol{\nabla}^{(1)}+\boldsymbol{\nabla}^{(2)}+\cdots+\boldsymbol{\nabla}^{(k)}+\cdots \\
& =\nabla^{(0)}+\varepsilon \boldsymbol{\nabla}^{(0)}+\varepsilon^{2} \boldsymbol{\nabla}^{(0)}+\cdots+\varepsilon^{k} \nabla^{(0)}+\cdots
\end{aligned}
$$

$$
\begin{aligned}
& \frac{D}{D t}=\frac{D}{D t^{(0)}}+\frac{D}{D t^{(1)}}+\frac{D}{D t^{(2)}}+\cdots+\frac{D}{D t^{(k)}}+\cdots \\
& \quad=\frac{D}{D t^{(0)}}+\varepsilon \frac{D}{D t^{(0)}}+\varepsilon^{2} \frac{D}{D t^{(0)}}+\cdots+\varepsilon^{k} \frac{D}{D t^{(0)}}+\cdots
\end{aligned}
$$

ここで，演算子の上付き添え字 $(k=0,1,2, \cdots)$ は現象のス ケールを表しており, 数字が増えるほど微視的スケー ルにおける演算子であると解釈する. 微小パラメータ 一 $\varepsilon$ は以下のように定義する.

$$
\varepsilon=\frac{\delta}{L} .
$$

式中， $\delta$ は界面を特徴付ける代表長さであり， $L$ は流 体渦運動の代表長さである $(\delta<L)$. 式(36), 式(37) の $\varepsilon$ の 2 次以上の高次項を省略してNS方程式(35)に代 入すると,

$$
\begin{aligned}
& \rho \frac{D\left(\boldsymbol{u}+\varepsilon \boldsymbol{u}^{\prime}\right)}{D \boldsymbol{t}^{(0)}}= \\
& -\nabla^{(0)}\left(P+\varepsilon P^{\prime}\right)+\nabla^{(0)} \cdot\left(\tau+\varepsilon \tau^{\prime}\right)+\boldsymbol{g},
\end{aligned}
$$

となる. 式(39)において, $\boldsymbol{u}, P, \boldsymbol{\tau}$ は巨視的スケールにお ける物理量を表しており，それぞれ流体の速度，機械 的圧力, せん断力である. ここで，機械的圧力を $P_{\text {mech }}$ と表す. $\varepsilon$ が掛かる項は微視的スケールにおける物理 量, つまり界面における物理量と解釈でき， $P^{\prime}$ は式 (34)の熱力学的圧力と同一である. $\boldsymbol{u}^{\prime} ， \tau^{\prime}$ は界面内に おける速度，せん断力である. このとき, 界面厚さが Kolmogorov スケールといった渦の最小スケールより 十分に小さいと見做すことにより，界面内の粘性は無 視できるものと仮定すれば， $\boldsymbol{\tau}^{\prime}$ は無視できる. 結局, 界面での微視的及び巨視的挙動を考慮可能なマルチ スケール混相流体方程式が次式のように得られる. 


$$
\begin{aligned}
& \rho \frac{D\left(\boldsymbol{u}+\varepsilon \boldsymbol{u}^{\prime}\right)}{D t}= \\
& -\nabla\left(P_{\text {mech }}+\varepsilon P_{\text {therm }}\right)+\boldsymbol{\nabla} \cdot \boldsymbol{\tau}+\boldsymbol{g} .
\end{aligned}
$$

ここで, 上付き添え字(0)は省略している. 現在, Phase Field 法を流体解析に応用している研究では, NS 方程 式中に熱力学的圧力 $P_{\text {therm }}$ の他に, 非対角項 $\nabla \psi \otimes \nabla \psi$ が存在する $^{(9)}$ （11) 。この項は格子気体モデルにおい て, 隣接格子点だけでなく, 対角の格子点の相互作用 を考慮に入れることで人工的に取り入れられている と考えられる ${ }^{(12)}$. 一方で, 熱力学的な観点からこの 非対角項を導出している研究もある ${ }^{(13)}$. しかしなが ら, 式(40)中の $\boldsymbol{\nabla} P_{\text {therm }}$ 項のテンソル解析から, 本研究 における手法においても非対角項及びそれに付随す る項が含まれていることが明らかになった. 以下がテ ンソル解析により変形された $\boldsymbol{\nabla} P_{\text {therm }}$ 項である.

$$
\begin{aligned}
& -\nabla P_{\text {therm }}=\nabla\left(f_{0}(\psi)+\frac{d}{4}|\nabla \psi|^{2}-\frac{d}{2} \psi \nabla \cdot \nabla \psi\right) \\
& +\frac{d}{2} \nabla \cdot(\nabla \psi \otimes \nabla \psi)+\frac{d}{2} \psi \nabla(\nabla \cdot \nabla \psi) .
\end{aligned}
$$

この考察により, $\nabla P_{\text {therm }}$ 項が熱力学的な圧力を表すよ り一般的な式形と結論できる.

本研究で導出したマルチスケール混相流体方程式 で拡散などの物質移動を取り扱う際には, 自由エネル ギーを汎関数微分して得られる以下の化学ポテンシ ヤルが重要となる.

$$
\mu=\frac{\delta F}{\delta \eta}=\frac{\delta \psi}{\delta \eta} \frac{\delta F}{\delta \psi} .
$$

ここで, $\delta \psi / \delta \eta$ は $\psi$ と $\eta$ で関連付けられた係数であ る. $\delta F / \delta \psi$ から $z_{\mathrm{i}} e V_{\mathrm{e}}$ 項が導出でき, この項は電気 化学における電気化学ポテンシャルに相当すると考 えられる. 式(42)は流体連動のスケールだけでなく物 質拡散のスケールでも重要である.

\section{5 結部}

本研究では，界面をある種の流体膜と仮定し，熱力学及び 数学的観点から気液界面のマルチスケールモデルの構築を 試みた。具体的には，界面に想定した污れ物質による電気 二重層の効果を考慮に入れ，自由エネルギーを導出した. そして, その自由エネルギーをChapman-Enskog 展開を用い て時間・空間スケールを区別することにより NS 方程式に 適用し，メソスケールの概念に基づた新たなマルチスケ 一ル混相流体方程式を導出した. この界面モデルは，気泡 の合・・分裂挙動，フォームの次元膜内流動，界面動電 現象等の界面現象の解明に繋がるものと考えられる. さら
に，物理及び化学的過程は自由エネルギーを介して関連付 けることが可能であり, 式(42)を応用することにより実現で きると考えているが, 流体運動及ひ物質拡散の両者を数值 解析の中で同時に取り扱うには，式(40)中における式(42)の 時間・空間スケールに関する更なる考察が必要であると考 えている.

\section{文萳}

(1) Brackbill, J. U., et al., Continuum method for modeling surface tension, J. Comput. Phys., Vol. 100 (1992), pp. 335-354.

(2) Craig, V. S. J., Bubble coalescence and specific-ion effects, Curr Opin Colloid Interface Sci, Vol. 9 (2004), pp. 178-184.

(3) Rowlinson, J. S. and Widom, B., Molecular theory of capillarity, (1984), Oxford University Press

(4) Cahn, J. W. and Hilliard, J. E., Free energy of a nonuniform system, I. Interfacial energy, J. Chem. Phys., Vol. 28, No.2 (1958), pp. 258- 267.

(5) Safran, S. A., Statistical thermodynamics of surfaces, interfaces, and membranes, (1994), pp. 63-66, Addison-Wesley Publishing Company.

(6) Fialkowski, M., et al., Scaling of the Euler characteristic, surface area, and curvatures in the phase separating or ordering systems, Phys. Rev. Lett., Vol. 86, No.2 (2000), pp. 240-243.

(7) Yonemoto, Y., et al., Study on bubble shape interacted with vortex motion via mathematical approach, American Physical Society 58th Annual Meeting of the Division of Fluid Dynamics, Vol. 50, No.9 (2005), p. 250.

(8) Chapman, S. and Cowling, T., The mathematical theory of non-uniform gases, (1970), 3rd Edn. Cambridge University Press.

(9) Jacqmin, D., Calculation of Two-phase Navier-Stokes flows using phase-field modeling, $J$. Comput. Phys., Vol. 155 (1999), pp. 96-127.

(10) Swift, M. R., et al., Lattice Boltzmann simulation of nonideal fluids, Phys. Rev. Lett. Vol. 75 (1995), pp. 830-833.

(11) Takada, N., et al., A phase-field method for interface-tracking simulation of two-phase flows, Math. Comput. Simulation, Vol. 72 (2006), pp. 220-226.

(12) Evans, R., The nature of the liquid-vapour interface and other topics in the statistical mechanics of non-uniform, classical fluids, $A d v$. Phys., Vol. 28 (1979), pp. 143-200.

(13) Antanovskii, L. K., Microscale theory of surface tension, Phys. Rev. E, Vol. 54, No.6 (1996), pp. 6285-6290. 